on their faces; diagnosis is shaped by the Kuhn's 'paradigms'), and there is no such thing as an atheoretical symptom language: every map has its grid, every picture its frame. Indeed, the psychiatric diagnostician, he suggests, should be seen as a cross between a botanist cataloguing flowers in the garden and a sculptor carving shapes out of marble. Viewed over time, these disease taxonomies reveal remarkable 'ruptures' (Bachelard's term), as is here demonstrated in subtle case studies of delusions, delirium, dementia and a hundred other conditions.

Berrios is far too astute an historian to offer any simple reductionist explanations for shifts in disease classification. He suggests our best explanatory bet lies in the clinician's cognitive frame (Thomas

model of change developed by the great French historian Fernand Braudel, with its harmonic interplay of short-, mediumand long-term forces. New theoretical schemes have always been important, but so have practical factors, for example the opportunities for the study of symptoms that were afforded by the invention of photography.

Berrios sees his book as a beginning. For the meantime, he has put us deeply in his debt with a remarkable account of the mappings of the mind through a study that transcends the private technicalities of psychiatry to shed light on the changing representations of the Western psyche itself.

Roy Porter is at the Wellcome Institute for the History of Medicine, 183 Euston Road, London NW1 2BN, UK.

\section{Pheromones, drugs and exploding bugs}

Tristram D. Wyatt

Bombardier Beetles and Fever Trees: A Close-Up Look at Chemical Warfare and Signals in Animals and Plants. By William Agosta. Addison-Wesley: 1996. Pp. 224. \$25.

Chemical Ecology: The Chemistry of Biotic Interaction. By Thomas Eisner and Jerrold Meinwald. National Academy Press: 1995. Pp. 214. \$49.95, £34.95.

POISON arrow frogs, the arms race between plants and their insect herbivores, and lobsters calling for mates are all examples of chemical defences or signals. They form part of a hidden chemical world of exquisite variety and subtlety only recently revealed to us.

Chemical interactions between organisms are explored in these two new books. William Agosta's is written for lay people whereas Thomas Eisner and Jerrold Meinwald's intended audience is the wide scientific community, from student to researcher. Both books offer a showcase for chemical ecology, a subject coming of age as advances in chemistry are combined with more sophisticated ecological, as well as molecular, studies. A good case is made by both books for the intellectual excitement of chemical ecology, but both also focus on its great practical uses in, say, drug discovery - cyclosporin and ivermectin being recent examples.

Eisner and Meinwald bring together a fine collection of chapters from a symposium on chemical ecology. The subjects range from chemical defences used by animal and plants, pheromones in ant colony organization, algal pheromones, sexual selection based on chemicals, eavesdropping and deceit by predators and parasites, through to the production and reception of pheromones and other signals at the molecular level. It is deliberately not an exhaustive survey: most chapters start with an overview and then focus on a particularly well-studied model system, such as aquatic chemical signals which are beautifully illustrated by lobsters, signal transduction by activation of helper $\mathrm{T}$ cells, and nervous-system processing of signals by the moth brain/ pheromone system. (The lack of a chapter on mammal or other vertebrate pheromone systems is a shame.)

Although some chapters contain familiar stories, all offer first-rate accounts of recent advances and give excellent examples. Most chapters are lively and there are some useful photographs. Surprisingly, there are no links between chapters. The strength of the book is its range, from ecology and evolution to molecular mechanisms. It succeeds as an exciting introduction to chemical ecology.

Agosta's subtitle is "chemical warfare and signals in animals and plants", but his book, although touching on many examples covered in Eisner and Meinwald's volume, includes much more than this. His theme is chemical adaptation in the broadest evolutionary sense. Structural chemical adaptations of spider silk and deer antlers are found alongside the chemical duets of fungus hyphae and the more familiar moth sex pheromones. The chemical adaptations of ice-fish and mites for coping in Antarctica, the production of light in fireflies and the use of pigments in animal colours are also covered. There is inevitably some overlap of material with the author's well-received Chemical Communication (W. H. Freeman/Scientific American Library, 1992), but this is small. The examples are up to date and the text is well edited. Two things that would improve the next edition are suggestions for further reading (or references - possible and useful even in popular books) and better illustrations.

Agosta is adept at handling controversial topics such as the existence of human pheromones for attraction between the sexes, and does not present them as cut and dried. He is also good at linking topics to their human interest. For example, he addresses environmental issues when comparing pesticides with the alternatives offered by microbial insecticides or by mating disruption with pheromones, and looks at the wider issues of drugs such as quinine and morphine. Particularly nicely done is his description of chemical cues in the life cycle of two parasites that affect millions of people: the tropical plant parasite Striga, or witchweed, with its minefield of seeds ready to germinate when crops are planted; and the complex life history of the schistosomiasis parasite, from snail to people.

Agosta's book is a lucid account of the chemistry behind the natural world. As part of the current renaissance in popular science books written by leading scientists, it may help to do for chemistry what others have done for evolution and genetics.

Both books end with the theme of biodiversity and its value - for drug discovery and much more - and the devastating threats to it from species extinction, especially through tropical deforestation. It seems likely that most species will be lost even before they have been described, let alone investigated for their chemical interest. Chemical ecologists can provide us with powerful arguments for species conservation.

Tristram D. Wyatt is in the Departments of Continuing Education and Zoology, University of Oxford, Oxford OX1 2JA, UK. 